\title{
A construção de mundos em fotografias de representações: supressão e ambigüidade em Robert Doisneau
}

Greice Scheneider e José Benjamim Picado Universidade Federal da Bahia/UFB 


\section{Resumo}

O propósito deste artigo é o de examinar o alcance de certos operadores de análise de materiais fotográficos, a título de uma exploração a certos aspectos do estilo de composição do fotógrafo francês Robert Doisneau (1912/1994): estamos especialmente de acordo com o papel exercido pela ambigüidade, própria às situações visuais geradas por suas fotografias, na configuração de um efeito de discurso para estas imagens (transformadas em sucedâneos de pequenas narrativas, quase sempre tingidas de um humor cômico). Procuramos avaliar a efícácia desta ambigüidade, a partir de noções como as da necessária incompletude dos aspectos visíveis na representação visual, assim como o da necessária cooperação que esta parece suscitar da parte do espectador (noçôes estas que derivam sobretudo das lições de Gombrich e de Goodman sobre a ontologia da representação).

\section{Palavras-chave}

fotografia, efeito de discurso, representação, Robert Doisneau

\section{Abstract}

The purpose of this article is to examine the range of certain categorires of analysis of photographies, by means of an exploration of cerain aspects of the compositional style of French photographer Robert Doisneau (1912/1994): we are specificaly concerned with the role exherted by ambiguity, proper to the visual situations generated by his photographs, in the configuration of an effect of discourse to these images (these transformed in the succedanea of short narratives, almost always tinctured with comic humour). We intend to evaluate the efficacy of that ambiguity, departing from notions such as that of necessary incompleteness of the visible aspects of visual representations, together with the consequential cooperation that it demands from the part of the beholder (notions mainly derived from the lessons of Gombrich and Goodmen on the ontology of representation).

\section{Key words}

photograph, ????, representation, Robert Doisneau 


\section{A ambigüidade e rendição das ações: como a fotografia vê as esculturas}

$\mathrm{N}$

osso tema é o do efeito de discurso atribuído às estruturas visuais da representação na fotografia: com este mesmo fim, já

empreendemos explorações sucessivas aos marcos teóricos da discussão acerca do estatuto da iconicidade visual, no território da semiótica e das teorias da arte; já examinamos, por exemplo, a pouca incidência que esta discussão teve para o tratamento da questão do discurso visual nas teorias da fotografia. ${ }^{1}$

Neste ponto, entretanto, não nos interessa reiterar tais pontos de partida puramente teóricos, mas sim explorar as implicações mais propriamente analíticas do exame de materiais fotográficos, de modo a extrair dos mesmos alguns elementos balizadores de nossas concepções acerca da discursividade visual na fotografia.

Em nossas incursões anteriores à análise do status discurșivo das imagens fotográficas, sedimentáramos nosso foco de interesse no que nos parecera ser a manifestação mais franca de nossas teses sobre a modelação icônica do discurso visual na fotografia: tomamos, com este propósito, a questão da representação das ações humanas, partindo dos paradigmas pictóricos da representação enquanto modelares para a relação entre fotografia e discurso visual. ${ }^{2}$

Neste patamar de análise, verificáramos que o caráter reportativo das imagens fotográficas não poderia ser firmado pelas

1. Cf. Picado, José Benjamim. "O Problema do iconismo: um dogma semiótico". In: DeSignis: revista de la asociation española de semiótica. 4/1 (2003): pp. 61,74.

2. Cf. Picado, José Benjamim. "Os desafios metodológicos da leitura das imagens: um exame crítico da semiologia visual". In: Fronteiras: estudos mediáticos. 4/2 (2003): pp. 56,70 . 
teses (predominantes na história das teorias da fotografia) que valorizavam em excesso o papel do dispositivo mecânico da fotografia na constituição de seus efeitos propriamente comunicacionais: em nosso modo de entender, a questão da rendição das ações no fotojornalismo, numa perspectiva semiótica, não poderia se dar pela dispensa dos repertórios analíticos que as teorias da arte, entre tantas outras, propiciaram para a explanação do mesmo fenômeno, no campo da pintura e da escultura. ${ }^{3}$

Entretanto, como já dissemos, o que nos interessa agora é a exploração de um universo empírico de análise que nos ajude (do mesmo modo que no caso das fotografias de ações humanas) na interrogação sobre a rentabilidade das chaves metodológicas que empregamos até este ponto. No que diz respeito ao problema da vigência de um paradigma pictórico na interpretação de imagens fotográficas, poderemos inclusive relativizar um tal princípio de análise: no caso das pequenas cenas visuais que iremos analisar aqui, o mais importante é que possamos reconhecer nos aspectos materiais das imagens, o mesmo tipo de pregnância que uma visão pictorialista pôde proporcionar para as fotografias de ação.

No caso das situações fotográficas que apresentaremos, a ten-

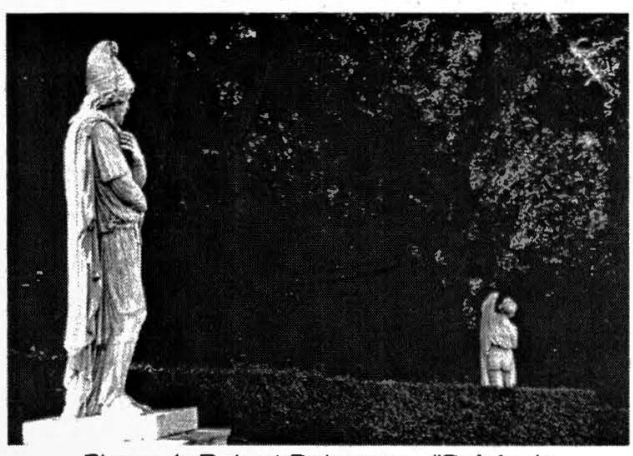

Figura 1: Robert Doisneau - "Palais de Versailles" (1966) são gerada pela imobilização dos elementos numa cena visual pareceria constituir um padrão de correção algo exclusivo da arte e da compreensão de fotografias: a ambigüidade e o poder de sugestão que lhe são próprios dificilmente poderiam ser encontrados nos exemplares da iconografia pictórica clássica ou narrativa. Vejamos agora como isto ocorre, considerando esta foto de Robert Doisneau (fig.1).

3. "Cf. Gombrich, E.H. "Standards of truth: the arrested image and the moving eye". In: The Image and the Eye: further studies in the psychology of pictorial perception. London: Phaidon, 1982, pp. 244,277. 
Vemos, nesta fotografia, duas estátuas, que estão num jardim do Palais de Versailles: o que parece nos interessar é o modo pelo qual Doisneau arranjou a disposição de seu olhar em relação a estas duas figuras (poderíamos dizer, como as compôs, fotograficamente falando), de maneira a nos suscitar a impressão bem vívida de uma cena, na qual as duas esculturas parecem implicadas num certo diálogo romântico; a suposta interação entre as imagens faz a graça desta foto, e seu procedimento básico consiste em equiparar o status ontológico destes objetos inanimados com o de possiveis seres vivos, a partir de um jogo de ambigüidades que parece, ao menos para alguns autores, mais próprio à fotografia do que à pintura.

Um primeiro aspecto que faz saltar à análise a questão do efeito de ambigüidade obtido fotograficamente já se adiantou aqui pelo modo como falamos da disposição visual dos elementos da cena para o dispositivo fotográfico: ele diz respeito, portanto, ao modo como o olhar do fotógrafo se dispõe para o motivo oferecido por estas duas figuras. Doisneau, certamente, reconhece que a disposição das esculturas no jardim visava originalmente a este efeito de ambigüidade, para um observador disposto precisamente na posição em que ele se localiza com sua câmera; o procedimento fotográfico aqui emula, por assim dizer, o olhar de um sujeito que se dispõe a observar as criaturas de uma tal perspectiva, e que lhe permita vislumbrar este interessante diálogo que elas mantêm neste espaço físico.

$\mathrm{Na}$ exploração da utilização de motivos escultóricos na fotografia, alguns pesquisadores ressaltam os possíveis aspectos que tornam o efeito de ambigüidade aqui obtido como sendo mais eficaz na fotografia do que quando ocorre como tópica pictórica: a capacidade dos dispositivos fotográficos para render visualmente certos aspectos de textura visual dos objetos parece ser uma das razões pelas quais este efeito de ambivalência é mais notável nas fotografias; não devemos subestimar, por outro lado, que é justamente o fato de ser uma fotografia em preto-e-branco que permite a Doisneau equalizar o caráter imóvel dos motivos com a sugestão de mobilidade, por sua vez própria a seres animados.

Seja como for, a ambigüidade na qual se enraíza o efeito de transformação, próprio às fotografias, parece aqui dizer respeito ao 
investimento de uma potencial motricidade às figuras visuais, originalmente estéticas: as estátuas são figuradas na sua imobilidade, mas pelo modo como a fotografia as investe (por exemplo, equiparando suas relações com o ambiente restante, pela adoção dos tons de cinza), somos levados a interpretar que estão vivas: a reversibilidade entre ser uma representação e ser um ente real é instaurada primeiramente aqui pela variação entre o animismo a imobilidade das figuras representadas. ${ }^{4}$

\section{Da ambigüidade à percepção do instante: o que significa ver fotografias}

Pensamos, entretanto, que a análise deste problema da essencial ambigüidade que demarca o fenômeno da representação das ações não deveria isolar em domínios necessariamente distintos os dispositivos da representação na fotografia e na pintura, por exemplo: na perspectiva que avançamos, o efeito de animação de figuras estáticas na fotografia requereria uma maior atenção de nossa parte sobre o estatuto que a representação das ações tem para as artes da pintura e da escultura, por exemplo.

Se assumirmos esta hipótese de partida, o problema da ambigüidade originária do status ontológico dos objetos da representação na fotografia não teria enraizamento exclusivo na natureza do dispositivo técnico da fotografia, mas também no plano de uma compreensão sobre a faculdade da "percep̧̧ão do instante": é no patamar desta modalidade da visão que podemos compreender o fenômeno de integração das ações no nível de um momento pregnante, além do valor que ele estabelece para a construção da representação visual, independentemente da natureza do dispositivo empregado.

Para certos autores, este é o problema que justifica uma tematização mais grave das operações estéticas através das quais

4. Cf. Savendoff, Barbara. "Transformation in photography". In: Transforming Images: or how the photopgraphy complicates the picture. Ithaca: Cornell University Press (2000): p. 47,128. 
encontramos tantas vezes em representações visuais figuras imóveis que ganham, de súbito; alguma animação. ${ }^{5}$

Como a fotografia suprime algumas das coisas que fariam com que distinguíssemos estátuas de seres humanos (no caso, o movimento principalmente) ficamos na dúvida, hesitamos por

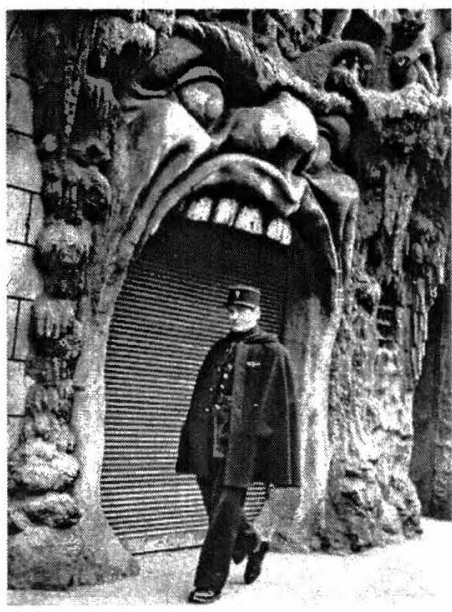

Figura 2, Robert Doisneau -

"Enfer" (1952) um momento, somos conduzidos deliberadamente a uma forma de ambiguiidade que instaura o efeito de urgência de desdobramento, próprio à percepção de uma ação, rendida pictoricamente. $\mathrm{O}$ exemplo seguinte de Doisneau (fig.2) amplia alguns aspectos da construção deste efeito de ambivalência na fotografia.

De modo ainda mais radical do que no caso anterior, aqui vemos um forte investimento daquela ambigüidade de status ontológico atribuído aos motivos da composição: se, no primeiro caso, víamos duas estátuas como se mantivessem um diálogo entre si (isto é, tomadas como sendo ambas igualmente animadas), aqui temos uma equiparação possível entre um ser inanimado (um portal estilizado como uma enorme boca aberta) e um ser vivo (um guarda parisiense que passa desavisadamente à frente do portal), o que gera um efeito inusitado de uma cena na qual o portal avançaria em direção ao pequeno homem, prestes a devorá-lo.

Num primeiro aspecto de nossa visada, a estrutura na qual a ambigüidade instaura a sensação de uma cena é a mesma na qual observáramos a fotografia anterior: o efeito de discurso próprio a esta foto se origina a partir do momento em que o objeto inanimado (o portão), de alguma maneira, ganha vida, tornando possível imaginar uma interação entre ele e o policial. A maneira pela qual o

5. Cf. Gombrich, E.H. "Reflexões sobre a revolução grega", In: Arte e llusão: um estudo da psicologia da representação pictórica (trad. Raul de Sá Barbosa). São Paulo: Martins Fontes, 1995, pp. 123,156. 
fotógrafo realiza este efeito é, em primeiro lugar, por suprimir do elemento supostamente animado (o policial) aquele aspecto que justamente lhe confere vida, sua motricidade. Restituído à mesma imobilidade do portal, ele entra em relação mais intensa com este motivo, ao menos na perspectiva de uma visão da representação.

Do ponto de vista da disposição do olhar fotográfico, o artista deve fixar o instante que faz com que os objetos inanimados se equiparem aos animados, visto que ambos se encontram na mesma condição. Susan Sontag já dizia que um dos sucessos mais permanentes da fotografia foi a estratégia de transformar seres vivos em coisas e coisas em seres vivos (Sontag, 1981, p.92).

$\mathrm{Na}$ origem do efeito próprio a fotos de esculturas, a falta de movimento própria à fotografia é muitas vezes um aspecto explorado pelo fotógrafo: sendo o fato de ser inanimado o aspecto que diferencia mais claramente os objetos e os seres vivos, a imobilização geral promovida pelo efeito de arresto temporal da imagem (próprio, mas não exclusivo dos dispositivos fotográficos) se revela como uma vantagem, na construção dos efeitos de ambigüidade que instauram o sentido de pequenas narrativas visuais na fotografia. O motivo proposto em "Enfer" toma mais dificil distinguir o que é móvel e o que não é: dessa forma, a impressão de urgência e de desdobramento, próprio à visão das ações (a sensação de que o policial estaria prestes a ser engolido), só poderia ser produzida a partir desse recurso.

Na vida neal, as representações nos impressionam como inanimadas. Elas são, em geral, estáticas, num mundo no qual cosas vivas se movem. A fotografia de still minimiza esta distinção entre o animado e o inanimado. As pessoas e coisas são ambas apresentadas sem que tenham movimento. $E$ mesmo quando este é sugerido, uma equivalência entre animado e inanimado pode ser estabelecida.(Savedoff, 2000, p.67)

Não devemos supor, entretanto que estas cenas fotográficas . se constituam rigorosamente enquanto falsas apreensões da realidade que supostamente se instauram como um efeito de realidade: não podemos subestimar o valor da ambigüidade perceptiva sobre a qual 
seu efeito está fundado; o significado da ilusão que propiciam (quando vemos estátuas como seres animados, ou portais que engolem pessoas) não pode ser confundido com uma falsa consciência, ou com uma impressão enganosa dos fatos, uma espécie de trompe l'oeil. Neste ponto, devemos ter em conta o papel que o dispositivo fotográfico exerce na impressão de veracidade, de algum modo associada a estas imagens: a transparência que atribuímos, por hábitos interpretativos, ao significado indexical da fotografia, nos impede de tomar estas imagens como reles fabricações, mas, mais propriamente como comentários irônicos sobre as possiveis relações entre as coisas do mundo, quando as dispomos para um olhar que segmenta sua duração ou equaliza certas de suas propriedades para uma visão, por assim dizer, pitoresca. ${ }^{6}$

Em suma, não duvidamos, ao vermos as fotos, de que o portão seja, de fato, um portão, e de que estátuas sejam, de fato, apenas estátuas, e de que ambos sejam, por definição, inanimados. $O$ efeito que estas imagens suscitam em nosso modo de compreender representações não afeta o estatuto ontológico destes seres, em nossa lida ordinária com os mesmos.

O que nos é requisitado, no plano da ambigüidade originária do efeito ao mesmo tempo plástico e discursivo destas imagens é que estamos lançados a um regime no qual as imagens são, por assim dizer, modos de fazer mundos: nestes termos, uma representação pode nos apresentar a um portão que deva se parecer com um monstro, do mesmo modo que estátuas podem conversar entre si. $\mathrm{O}$ comentário jocoso que parece estar subentendido nestas imagens requer que o jogo do reconhecimento de seus objetos contemple um aspecto de ficção, associado à fotografia: nada disto seria possivel se nos mantivéssemos estritamente no plano de uma correlação prédeterminada entre representação e realidade.

6. O problema da indexicalidade originária das imagens fotográficas é motivo de um discurso fortíssimo nas teorias da fotografia, cuja enorme extensão não nos interessa restituir aqui. Apenas indicamos, a título de referência, uma sümula de muitas destas posições teónicas, na letra de Kendąl Walton. Cf. "Transparent pictures; the nature of photographic realism" In: Critical Inquiry. 11, 1984, pp. 246,277 . 


\section{Seletividade e completação: a fotografia e os modos de fazer mundos}

Se podemos acatar que o procedimento próprio ao olhar do fotógrafo é o de uma seleção de aspectos e de dimensões espaciais e temporais de seus motivos, então devemos nos interrogar sobre qual é o papel do espectador neste processo, ou de que maneira é que o apreciador constrói nela seus devidos sentidos. Em Nelson Goodman, por exemplo, podemos ter algumas indicações do que se passa neste processo: numa perspectiva própria à filosofia das formas simbólicas de Cassirer, longe de ser um registro passivo dos fatos, a visão, na arte ou no dia-a-dia, é um elemento verdadeiramente criador da realidade (D'Orey, in: Goodman, 1995, p.25).

No caso da interpretação da fotografia, nos interessam especialmente as modalidades de construção a que Goodman designa como sendo a supressão e a completação: estas duas modalidades implicam o fato de que a nossa capacidade para não ver é virtualmente ilimitada, e aquilo que assimilamos consiste habitualmente em fragmentos significativos e pistas que precisam de completação massiva (Goodman, 1995, p.51).

Para Goodman, é comum encontrar justamente aquilo que estamos preparados para encontrar (o que procuramos ou o que vigorosamente afronta as nossas expectativds), e que provavelmente ficamos cegos para com o que nem ajuda nem impede as nossas buscas. (Idem, p.52).

Esse mesmo princípio pode ser encontrado na importância conferida por Gombrich a um certo estilo lacunar da representação (característico sobretudo da pintura do norte da Europa, no século XVII), e que suscita da parte do espectador um exercício ativo de completação de certos caracteres definidores da composição pictórica: ṇeste sentido, devemos ter em conta a influência que as expectativas e os saberes prévios podem exercer na interpretação de imagens, antes de considerarmos seu caráter representacional, na perspectiva de uma análise de suas propriedades puramente internas. 
Na apreciação da representação visual, nos pomos em um jogo de tentativa e erro, e somos instados a preencher certos espaços vazios das imagens, sendo precisamente neste aspecto que a ambigüidade das imagens implica uma certa pragmática da representação visual. Nestes termos, o que temos em vista é um certo princípio de cooperação interpretativa (tão cara a certas tradições nas teorias da literatura, mas também com repercussões no campo da interpretação das imagens). ${ }^{7}$

A supressão e completação que Goodman menciona, então, dizem respeito aos caprichos da memória em completar aspectos que não estão nas imagens, assim como em suprimir caracteres que lá estejam, tudo isto a partir da comparação com outros mundos já existentes. É justamente a lida com essas lacunas que interessa a esse trabalho: em nossa perspectiva, a construção de uma cena visual, na modalidade em que a vemos exercida por Doisneau, implica na admissão de um valor estrutural para estas operações de sentido com as elipses: elas têm tanto um valor indutivo. quanto fenomenológico, isto é, se explicam tanto pelas operações que o artista realiza para produzir suas representações, quanto pelos gêneros de experiência visual sobre os

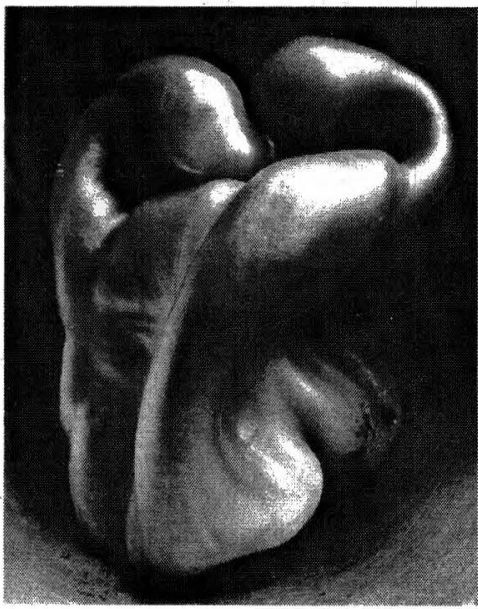

Figura 3, Edward Weston - "Pepper" (1930)

quais estão enraizados. No caso especial da fotografia, podemos sobretudo considerar as elipses de tridimensionalidade, de textura, de movimento, por vezes de cor, entre tantas outras.

Se tomarmos os exemplos das fotografias de pimentões de Edward Weston (fig. 3), poderemos contemplar verdadeiros convites

7. Sobre o assunto, consultar as referências ás relações entre a noção de implicitude na atividade da leitura, na perspectiva das teorias estéticas da recepção (especialmente, em Wolfgang Iser), a teoria semiótica da interpretação como principio de cooperação textual (em Umberto Eco), e a teoria da representação pictórica como fundada na cooperação e na atividade do espectador, em E.H.Gombrich. 
às operações de completação, assim como as manchas usadas nos exames de Rorschach, fundadas do mesmo modo numa espécie de inclinação projetiva, própria à percepção visual. Weston chega perto dos objetos, faz cortes, enfatiza texturas, orientando o espectador a ter uma determinada posição. Pode-se falar, inclusive, de um valor associativo destas imagens, ligado a seu poder de sugestão de um indubitável erotismo.

Ao que parece, é algo próprio ao dispositivo fotográfico da representação que instaura este efeito pelo qual associamos a visão de pimentões com a do significado erótico de corpos torneados e atraentes: não implicariamos nesta ordem de coisas a visão de pimentões "ao natural", sendo que a supressão e o anamorfismo de certos aspectos do objeto que suscitam esta relação com seres animados.

Em geral, mais uma vez, é comum atribuirmos a eficácia destas associações às propriedades do dispositivo fotográfico: supomos, por exemplo, que uma escultura que emulasse estes aspectos de torção e de animação, próprios à visão das formas, não nos suscitaria tão fortemente esta impressão de um corpo animado, que parece tão própria à percepção de fotografias: e, de fato, alguns autores insistem numa exclusividade do arché fotográfico na consumação deste efeito de animação das formas, próprio à anamorfose visual. ${ }^{8}$

$O$ caso das fotos de Weston é um exemplo mais extremado dos modos como esse fenômeno de supressão de aspectos da representação, uma vez aliado aos conhecimentos do apreciador sobre a especificidade da fotografia, pode criar mundos e produzir um efeito lúdico muito particular no espectador. Numa boa medida, este efeito decorre de uma certa ambigüidade, própria ao estilo lacunar de certas representações, e do caráter igualmente dúbio de seu preenchimento, no plano de sua percepção.

No caso das fotos de Doisneau, o aspecto de ambigüidade é, de algum modo reforçado pelo fato de que são postos em jogo objetos que possuem estatuto ontológico muito distinto: a presença de representações dentro do campo fotográfico, tomadas enquanto seres

8. Cf. Machado, Arlindo. "Cronolopic anamorphosis or the fourth dimension of the image". In: Visio. 4/1: pp. 43,53. 
animados, instaura um tipo de jogo perceptivo muito característico de um certo gênero de fotografias.

É importante ressaltar, contudo, que nem todas as fotografias de representações podem suscitar esse efeito de ambigüidade. Para que isso aconteça, é necessário que essas representações sejam inseridas em contextos nos quais elas possam ser lidas como os objetos que elas representam. No final das contas é contextualizando e descontextualizando os elementos da foto que se pode criar esse tipo de efeito. $O$ jogo com o contexto pode ser uma maneira de burlar a expectativa do espectador surpreendendo-o, chocando-o ou divertindo-o (Joly, 1996, p.63).

O espectador é convocado, junto com todo seu capital de experiência prévia, a ler as fotos como se fossem recortes da realidade, mas, ao se deparar com texturas de concreto e portões dentro de bocas, acaba percebendo que aqueles objetos fotografados são apenas representações. Ainda assim, o mundo da foto é regido por leis diferentes, e implora para ser decifrado como se fosse uma cena, investido do caráter de uma narrativas, ou de uma ficção. Assim, são os procedimentos de descontextualização familiares para nós e que deslocam o sentido de um campo a outro, brincando com o nosso saber e nossas expectativas. Alguns deslocamentos podem ser perniciosos, cabe a nós decifra-los de um a um. (Idem, ibidem)

\section{O lugar do dispositivo: indexicalidade e visões da representação na fotografia}

Vimos no início de nossa exposição que a caracterização de certas cenas visuais pareceria introduzir com maior propriedade do que em outros casos a questão das relações entre a ambigüidade do status ontológico de seus objetos (originária de seu efeito de discurso) e as características do dispositivo técnico da fotografia (originária do modo como estes objetos são rendidos na plano da representação). Este ponto envolve a admissão daquele fortíssimo discurso que aposta, entre outras coisas, no aspecto intrinsecamente indexical da significação da fotografia: gostaríamos 
de tecer algumas considerações sobre este ponto, antes de arrematarmos a questão da ambigüidade e da participação do espectador na construção do efeito de discurso, próprio à representação fotográfica.

Em todos os exemplos apresentados, o conhecimento do assim chamado arché fotográfico - isto é, o conhecimento acerca do dispositivo que carateriza a produção da imagem fotográfica, com as implicações ontológicas que isto acarreta para os motivos da representação - parece essencial para a obtenção deste efeito de ambigüidade e para que o papel da recepção seja requisitado na sua completação.

É bem verdade que a supressão de elementos também é possível em outros tipos de representação. $\mathrm{Na}$ pintura, a tridimensionalidade e o movimento (para ficar só nesses dois elementos) também são suprimidos, de tal sorte que podemos falar de uma idéia de experiência vicária de testemunho visual, muito antes do advento da fotografia enquanto dispositivo de representação. ${ }^{9}$

Entretanto, o desenho de um desenho que, na verdade, não é desenho ou o desenho de uma escultura que aparece como se estivesse se movendo não teriam (per hypothese) tanta eficácia em seu efeito lúdico, de ambigüidade. Podemos supor que as dificuldades impostas para o espectador para entrar em um jogo desse tipo são muito maiores na pintura do que na fotografia, justamente porque ele sabe que tudo o que está no quadro não é uma brincadeira de ponto de vista, produto de uma observação arguta ou coisa do tipo, mas foi deliberadamente criado pelo artista.

A transformação e equivalência encontradas na pintura se diferenciam em um importante aspecto em relação àquele atingido pela fotografia. Porque nós prontamente pensamos em pinturas como construções, nós vemos as equivalências e transformações que elas mostram como produtos da imaginação do artista. Por outro lado, por nós tendermos a pensar as fotografias como registros

9. Cf. Gombrich, Ernest H. "Moment and movement in art". In: The Image and the Eye. op.cit., pp. 40,62. 
objetivos do mundo, o fenômeno que elas apresentam, não importa o quão surpreendentes ou perturbadores eles sejam, não são tão facilmente descartados como ficções da imaginação.(Savendoff, 2000, p.81,82)

Para considerar o dispositivo importante na recepção das imagens, deve-se partir do pressuposto que a diferença na interpretação de uma fotografia e de uma pintura reside no conhecimento do espectador sobre a natureza do meio, tanto quanto sobre a natureza dos objetos da representação. Esse horizonte de expectativas é tão importante quanto o que há de semelhante entre esses dois tipos de imagem. Aceitar que o conhecimento da especificidade fotográfica - o assim chamado arché da fotografia - orienta nossa leitura dessas imagens é acolher a idéia de que existiria uma visão própria das fotografias.

A favor dessa idéia, pode-se identificar alguns defensores, como Richard Wollheim, por exemplo. Antes de falar especificamente de fotos, vemo-lo defender a existência de uma visão própria de representações, orientada pelo que ele chama de "padrão de correção", que, por sua vez, derivaria da intenção do artista. Como na fotografia, o processo de produção envolve muita causalidade e a figura do autor é menor, Wollheim defende a existência de uma visão própria à representação, mas especifica de fotografias.

Segundo ele,

os critérios de correção e incorreção aplicam-se à visão própria das fotografias, mas a participação de um processo mecânico na produção das fotografias faz com que a causalidade tenha sua importância no minimo equivalente à da intenção para o estabelecimento do critério de correção. (Wollheim, 1994, p.179)

Colocar o problema da intenção artística como determinante na visão de qualquer representação já é um movimento problemático, mas, de qualquer maneira, se abstrairmos essa parte do argumento, a idéia de visão própria das fotografias parece fazer algum sentido. 


\section{O conhecimento da arché e os modos da compreensão fotográfica}

Se existe uma visão própria de fotografias, é necessário, para seu bom funcionamento, que exista algo indicando que uma imagem foi ou não obtida fotograficamente. E só é possível identificar isso através da própria materialidade da foto, seja reconhecendo uma certa textura e brilho, por vezes a presença de granulação, entre tantos outros aspectos de sua composição. Se não podemos oferecer nenhuma indicação de que se trate de uma fotografia, ela pode ser tomada como uma espécie de representação. Nesse caso, ela deve ser vista da mesma maneira que se vê uma representação, ou seja, em conformidade com os mesmós padrões de correção (Idem, p.180).

Dada a incapacidade do receptor de decidir se se trata de uma foto ou dà reprodução de um quadro, a função indicial da imagem desaparece, o que afeta profundamente seu estatuto semiótico. Mas basta que uma indicação textual designe a imagem como fotografia para que a indicialidade ressurja, afetando, por sua vez, o estatuto dos retoques 'pictóricos'. (Schaeffer, 1987, p.42)

Evidentemente, é possivel reconhecer os elementos fotografados sem saber que uma imagem se trata de uma foto. Não há qualquer dificuldade em reconhecer rostos, objetos, variações de luz, formas etc. Quanto a isso, vale repetir, o princípio é equivalente ao da percepção visual de uma maneira geral. Contudo, existem determinados estados diante da foto que só poderão ser ativados se soubermos que aquilo é, de fato, uma fotografia, afinal, como diz Barbara Savedoff, a diferença das nossas reações a pinturas e a fotografias reside nas nossas crenças sobre suas origens. (Savendoff, 2000, p.10)

Ao se defrontar com una fotografia, o apreciador espera saber que as fotos são produzidas através de un recorte de dois eixos - no espaço e no tempo (diferentemente da pintura, na qual a imagem vai sendo construída pelo artista aos poucos, e com uma 
larga parcela de independência sobre o que vai se acrescentar na tela).

Todos estes fatos postos, entretanto, consideremos o ponto da questão que nos motivou a tematizar a fotografia nas suas relações possíveis com os efeitos de discurso: no caso da ambigüidade que cerca a produção deste efeito da cena visual, gostaríamos de ressaltar que o conhecimento do dispositivo é uma informação bastante importante, mas que deve ser tratada como dado de pressuposto e não como uma categoria analítica na interpretação do funcionamento desta imagem.

Certos comentadores tem chamado nossa atenção para o fato de que o estilo de determinados fotógrafos pode bem ser examinado pelos diferentes gêneros de disposição para o ato fotográfico, experiência esta que se define como um gênero de expectância: um modo não apenas de espreitar as ações ou a junção dos elementos de uma composição (e que caracteriza o ato de concentração próprio à arte do fotógrafo, e que se manifesta de modo razoavelmente diferenciado entre estes artistas); muitas vezes, nem mesmo se trata de um gênero de espera (como é claramente o caso da fotografia espontânea de um Cartier-Bresson), mas uma autêntica construção das condições nas quais o olhar fotográfico pode se programar de tal modo a chegar a uma composição a mais adequada aos propósitos requeridos (é expressamente o caso de um Sebastião Salgado). ${ }^{10}$

É muito evidente que este gênero de disposições não poderia jamais ser exercitado como uma faculdade inerente aos atributos da arte de um pintor, por exemplo, mas lembramos que nosso chamamento ao problema da expectância tem aqui um outro sentido: não se trata de supor que o ato fotográfico não se constitua como uma operação de base, no gênero das ações que caracterizam a fotografia enquanto um determinado tipo de imagem; sequer propomos que as faculdades requeridas ao fotógrafo não devam ser discriminadas, com algum grau de diferenciação, em relação às outras artes visuais.

10. Cf. Lissovsky, Mauricio. "O refúgio do tempo no tempo do instantâneo". In: AAW. O Othar Estético da Comunicação (lone Bentz et at., orgs.). Petrópolis: Vozes, $2000, \mathrm{pp} .101,123$. 
Nosso problema diz respeito à extensão na qual a estrutura deste ato determina, por exemplo, até mesmo os critérios pelos quais uma ação é segmentada ou arrestada, que uma expressão físionômica é destacada ao olhar ou que um conjunto de elementos inertes ou moventes confluam para um mesmo espaço, criando em nós a sensação de integração espacial e temporal.

Contudo, como vimos, o exame de fotografias expressivas como Versailles e Enfer, de Robert Doisneau nos revela que, ainda que não compareça expressamente na atividade analítica (uma vez que esta tem em vista os efeitos causados no espectador), não há como descartar o conhecimento do arché fotográfico como pressuposto fundamental para a compreensão de certos tipos de fotografias, especialmente nos casos examinados, que envolvem o efeito nesse texto denominado de ambiguidade fotográfica.

Ainda assim, é preciso reforçar a idéia de que esse poder de supressão, de corte no fluxo do tempo e no espaço, que é próprio à atividade fotográfica, só importa na medida em que o espectador tenha conhecimento disso, ou seja, é na esfera de recepção que o efeito se dá. $O$ ato fotográfico não suscitaria a impressão de ambiguidade caso nossos hábitos perceptivos desconhecessem seu funcionamento.

\section{Bibliografia}

GOMBRICH, E. H. The Image and the Eye: further studies in the psychology of pictorial representation. London: Phaidon (1982); Arte e Ilusão: um Estudo da Psicologia da Representação Pictórica (trad. Raul de Sá Barbosa). São Paulo: Martins Fontes (1995);

GOODMAN, Nelson. Modos de Fazer Mundos (trad. Antônio Duarte). Porto: Asa (1995);

JOLY, Martine. Introdução à Análise da Imagem (trad. Marina Appenzeller). Campinas: Papirus (1996);

LISSOVSKY, Maurício. "O refúgio do tempo no tempo do instantâneo". In: AAVV. O Olhar Estético da Comunicação (Antonio 
Albino Rubim, Ione Bentz e Milton José Pinto, orgs.). Petrópolis: Vozes (1999): pp. 101,123;

MACAHDO, Arlindo. "Cronotopic anamorphosis or the fourth dimension of the image". In: Visio. 4/1 (1999): pp. 43,53.

PICADO, José Benjamim. "Os desafios metodológicos da leitura de imagens: um exame crítico da semiologia visual". In: Fronteiras: estudos mediáticos. 4/2 (2003): pp. 56, 70;

" "O Problema do iconismo: um dogma semiótico". In: DeSignis. 4 (2003): pp. 61,74.

SAVEDOFF, Bárbara. Transforming Images: how photography complicates the picture. Ithaca: Cornell University Press (2000);

SCHAEFFER, Jean-Marie. A Imagem Precária: sobre o dispositivo fotográfico (trad. Eleonora Bottman). Campinas: Papirus (1996);

SONTAG, Susan. Ensaios sobre a Fotografia (trad. José Afonso Furtado). Rio: Arbor (1981);

WALTON, Kendall. "Transparent pictures; the nature of photographic realism" In: Critical Inquiry. 11 (1984): pp. 246,277;

WOLLHEIM, Richard. A Arte e Seus Objetos (trad. Marcelo Brandão Cipolla). São Paulo: Martins Fontes, 1994. 